\title{
Mathematical Prediction for BFRP Retrofitted after Fatigue Loading of Concrete Specimens
}

\author{
Dr. R.Anandakumar ${ }^{1^{\star}}$, Dr. M.S.Ravikumar ${ }^{2}$, Dr. C. Selvamony ${ }^{3}$ \\ ${ }^{1 *}$ Professor, Department of Civil Engineering, Mahakavi Bharathiyar College of Engg. \& Tech., Athuvali, India. \\ dr.ranandakumar@gmail.com \\ ${ }^{2}$ Professor, Department of Civil Engineering, PSN College of Engg. \& Tech., Melathediyoor, India. \\ ravikumar_ms@yahoo.com \\ ${ }^{3}$ Professor, Department of Civil Engineering, PSN College of Engg. \& Tech., Melathediyoor, India. \\ selvamony_2007@yahoo.com
}

\begin{abstract}
This paper deals with the experiment investigations on the Basalt Fibre Reinforced Polymer composites wrapped concrete specimens for determining the mathematical prediction for retrofitting of concrete specimens. For the past three decades, fibres are being effectively utilized in engineering fields. Some countries do not have specified codes for structural designing of Fibre Reinforced Polymer composites. Especially for this situation, the mathematical predictions were determined by experimentally for Basalt Fibre Reinforced Polymer composites retrofitted concrete. For this experiment, cubes, cylinders and prisms were cast using $\mathrm{M}_{30}$ grade concrete to analyze the characteristic strengths. The tests were carried out with and without Basalt Fibre Reinforced Polymer wrapping and retrofitted after 0\%, 30\%, 60\% and 90\% fatigue loaded or preloaded specimens. The retrofitted specimens with Basalt Fibre Reinforced Polymer wrapping, even after $90 \%$ fatigue loaded possess higher strength than conventional one. The observed readings were analyzed and mathematical prediction was developed by using readings and graphical representations. From the study, similar results were observed through experiments and mathematical predictions.
\end{abstract}

\section{Keywords}

Basalt Fibre, Polymer, Wrapping, Preloading, Retrofitting, Characteristic strength, Formula.

\section{Academic Discipline And Sub-Disciplines}

Civil Engineering

\section{SUBJECT CLASSIFICATION}

Polymer Composite

\section{TYPE (METHOD/APPROACH)}

\section{Experimental Analysis}

\section{INTRODUCTION}

Retrofitting means strengthening the deteriorated or damaged structures with suitable technology for keep the originality for long service. Retrofitting needs for safeguard the structure for long service and upgrade the load bearing capacity of structure. Generally, a structure is designed for a particular service period. In this period the structures may be affected due to fatigues, creep loss, wear, gradual loss of strength, multiple environments effects, natural hazards, etc. In these conditions, the structures should be retrofitted for extending the service life. In engineering field lot of retrofitting methods available such as coating, external stressing, grouting, guniting, jacketing, overlaying, re-baring, sealing, stitching, wrapping, underpinning etc. From these, the wrapping method is very simple and handy method to retrofit structures. Besides, it does not require heavy tools \& skilled labours. In this paper fatigued concrete specimens retrofitted with Basalt Fibre Reinforced Polymer composite (BFRP) wrapping for determining the strength by mathematical predictonly. According to that lot of research papers were reviewed and Fibre Reinforced Polymer (FRP) composite wrapping technique was studied.

The mathematical model was found to predict the effects of FRP lamination and the reduction in the steel reinforcement area due to corrosion on the beam. This model predicts the flexural response of corroded RC beams laminated using Carbon Fibre Reinforced Polymer composites (CFRP). Ten identical corroded FRP beams were experimented for compressive strength and flexural strength. Besides, computed with ACFRP-04 program and examined the accuracy of the mathematical model and it was found that the model accurately predicted the load-deflection relationship of corroded FRP beams which was observed in the laboratory [1]. Non-linear analysis had been made to predict the behaviour of CFRP confined concrete. Using finite element (FE) method, specific expressions for modeling of the non-linear behaviour of confined concrete specimens were presented. Using this expression CFRP confined specimen was modeled with ANSYS software. The presented expressions were verified with the results of experiments conducted for axial load and flexural moment. The result showed suitability of the model in terms of accurately representing the experimental results. 
Using this model, a variety of studies can be done on the confined RC column [2]. Steel fibre reinforced concrete (SFRC) had been experimented for split tensile strength and a mathematical model was created to predict tensile strength, knowing the values of $\%$ of fibre and aspect ratio. The 50,60 and 67 aspect ratio fibres in $0 \%, 1 \%$ and $3 \%$ volume fraction were used. SFRC with $3 \%$ steel fibre and 50 aspect ratio concrete gave higher tensile strength. Tensile strength was increased from 9 to $29 \%$ by using steel fibre. Besides, experimental results were compared with mathematical model; it shows fairly accurate results [3]. The compressive and split tensile strength of concrete with $0 \%$ to $3 \%$ plastic fibres had been observed and test results were compared. At $1 \%$ fibre content get maximum compressive strength, tensile strength and concrete become light in weight. The experimental results were compared with predicted equation that results were slightly low while compare with experimental results [4]. Comparison of compressive strength was carried out between GFRP and CFRP confined concrete after 7 days and 28 days water curing. An empirical model was created to predict the compressive strength of FRP confined concrete cylinders. Compressive strength of specimens, having fibres along the circumference was higher than that of the specimen with fibre along the length direction. CFRP specimens were attained more strength than GFRP specimens [5]. The reliability comparison was done between conventional RC members and steel fibre RC members using reliability index, which was derived from first order second moment method. Using $\mathrm{C}^{++}$ programme moment carrying capacity of a RC beams with $1 \%$ reinforcement and $0.75 \%$ steel fibre with aspect ratio of 90 . SFRC absorbed a large amount of energy and hence increased cracking moment and serviceability of the structure. There was an increase of $72 \%$ in the reliability index value [6]. A prediction equation had been presented to study the parameters of GFRP strengthened corrosion damaged RC columns. An accelerated corrosion technique was used to vary the level of corrosion on specimen as $0 \%, 15 \%$ and $30 \%$ level. Specimens were tested to examine the effectiveness of GFRP corrosion damaged RC columns. The GFRP wrapping was done with $3 \mathrm{~mm}$ and $5 \mathrm{~mm}$ thickness for each configuration. Experimental values were predicted with reasonable accuracy by regression model [7]. Author of this paper determined the performance of BFRP wrapped specimens under compressive, split tensile and flexural loads with single and double layer of unidirectional fibre and compared with conventional specimens after 7 days, 14 days and 28 days curing. The BFRP double wrapped specimens showed more strengths than conventional and single wrapped specimens [10]. Moreover, made clear investigations were carried out on the BFRP retrofitted specimens' performance. For retrofitting, the conventional specimens were preloaded to $30 \%, 60 \%$ and $90 \%$ of ultimate load of conventional elements; preloaded elements were retrofitted with BFRP composites by wrapping in two layer. Characteristic strength of $90 \%$ preloaded and retrofitted specimens were relatively more than conventional specimens [11-12]. In addition to this, studied durability aspects of the BFRP wrapped specimens by examining its resistance against heat and acid attack. Retrofitted specimens were much durable than conventional specimens [13].

The main objective of this research is to find out the mathematical prediction for specimens retrofitted with BFRP wrapping and validate it with experimental results.

\section{MATERIALS AND METHODS}

For this experiment 43 grade OPC cement was used as binding material and its properties were tested as per specifications of IS $8112^{14}$ \& IS $4031^{21}$ (part 4 to 15) [14-15].

Table 1. Properties of ingredients

\begin{tabular}{|c|c|}
\hline $\begin{array}{l}\text { Description of } \\
\text { Materials }\end{array}$ & Properties of materials \\
\hline $\begin{array}{l}\text { Cement - OPC } 43 \\
\text { Grade }\end{array}$ & $\begin{array}{c}\text { Specific gravity }-3.15 \mathrm{~kg} / \mathrm{m}^{3} \text {; fineness }-227.8 \mathrm{~m}^{2} / \mathrm{kg} \text {; initial setting time }-45 \mathrm{~min} \text {; Final setting } \\
\text { time }-585 \mathrm{~min} \text {; standard consistency }-36 \% \text {. }\end{array}$ \\
\hline Fine Aggregate & $\begin{array}{c}\text { Good river sand; size - } 4.75 \mathrm{~mm} \text { and down size; specific gravity }-2.8 \mathrm{~kg} / \mathrm{m}^{3} \text {; Fineness modulus } \\
\quad-3.1 \% \text {; water absorption }-0.5 \% \text {; surface texture -Smooth; particles shape- Angular. }\end{array}$ \\
\hline Coarse Aggregate & $\begin{array}{l}\text { Specific gravity }-2.8 \mathrm{~kg} / \mathrm{m}^{3} \text {; fineness modulus }-7.5 \% \text {; Impact value }-15.2 \text {; water absorption - } \\
0.5 \% \text {; Particle shape -Angular; crushing value -18.6; particles shape- Angular. }\end{array}$ \\
\hline Water & $\begin{array}{l}\text { Good potable; } p^{H} \text { Value- } 7.61 ; \text { chloride - } 420 \text { ppm; sulphite -10ppm; suspended (TDS) - } 890 \\
\text { ppm. }\end{array}$ \\
\hline $\begin{array}{l}\text { Basalt Unidirectional } \\
\text { Fabric }\end{array}$ & $\begin{array}{l}\text { Structures weaving - UD; weight - } 450 \mathrm{gram} / \mathrm{m}^{2} ; \text { thickness }-0.36 \mathrm{~mm} \text {; width } 600 \mathrm{~mm} \text {; warp } \\
\text { alone. }\end{array}$ \\
\hline Epoxy (Hardener) & $\begin{array}{l}\text { Aspect (visual) - white viscous paste; viscosity at } 25^{\circ} \mathrm{C}-70000-90000 \text { [mPa s]; density at } 25 \\
{ }^{\circ} \mathrm{C} \text { (ISO 1675)- } 1.0[\mathrm{~g} / \mathrm{cm} 3]\end{array}$ \\
\hline Epoxy (Resin) & $\begin{array}{c}\text { Aspect (visual)- clear, pale yellow liquid; viscosity at } 25^{\circ} \mathrm{C}(\text { ISO } 9371 \mathrm{~B})-10000-12000[\mathrm{mPa} \\
\text { s]; density at } 25^{\circ} \mathrm{C} \text { (ISO 1675) }-1.15-1.20[\mathrm{~g} / \mathrm{cm} 3] .\end{array}$ \\
\hline Steel - RTS - Fe 415 & Yield strength $-469.3 \mathrm{~N} / \mathrm{mm}^{2}$ \\
\hline Water & Good potable; $p^{H}$ Value- 7.61 ; chloride - 420 ppm; sulphite -10ppm; suspended (TDS) - 890 \\
\hline
\end{tabular}

5945 | P a g e

February 2017

w w w. cirworld. com 
ppm.

Locally available river sand were used as fine aggregate. The properties of both fine aggregates and coarse aggregates were tested as per IS 383 - 1970 specifications [16]. The properties of water were tested as per IS 3025 [17]. Basalt unidirectional fibres were used for confinement of specimens by using epoxy adhesive; the properties were obtained from the technical data sheet which was collected from manufacturer's m/s GBF Zhe Jiang Basalt Fibre Co., Ltd., China [18].Epoxy properties were collected form manufactures website [19]. Based on the materials test results, the M30 grade concrete was designed for specimens casting and testing as per IS code $10262-2000$ [20].The properties of the ingredient materials are enlisted in Table 1.Specimens like cubes $(150 \mathrm{~mm} \times 150 \mathrm{~mm} \times 150 \mathrm{~mm})$, cylinders $(150 \mathrm{~mm}$ dia. \& $300 \mathrm{~mm}$ length) and prisms (100mm $\times 100 \mathrm{~mm} \& 500$ length) were cast and tested for finding out the characteristic strengths such as compressive, split tensile and flexural strengths respectively after 7 days, 14 days and 28 days of curing as per Table 2 schedule. The tests were carried out in compressive testing machine and UTM as per IS code 516 - 1954 [21]. Experimental results were observed, analyzed and tabulated in Table 3.

Table 2. Schedule for casting and testing of specimens

\begin{tabular}{|c|c|c|c|c|c|c|c|c|c|c|}
\hline \multirow{2}{*}{ Specimens } & \multicolumn{3}{|c|}{ Conventional } & \multicolumn{3}{|c|}{ BFRP single wrap } & \multicolumn{3}{|c|}{ BFRP double wrap } & \multirow{2}{*}{$\begin{array}{c}\text { Orientation } \\
\text { of fibre }\end{array}$} \\
\hline & $\begin{array}{c}7 \\
\text { days }\end{array}$ & $\begin{array}{c}14 \\
\text { days }\end{array}$ & $\begin{array}{c}28 \\
\text { days }\end{array}$ & $\begin{array}{c}7 \\
\text { days }\end{array}$ & $\begin{array}{c}14 \\
\text { days }\end{array}$ & $\begin{array}{c}28 \\
\text { days }\end{array}$ & $\begin{array}{c}7 \\
\text { days }\end{array}$ & $\begin{array}{c}14 \\
\text { days }\end{array}$ & $\begin{array}{c}28 \\
\text { days }\end{array}$ & \\
\hline Cubes & 3 & 3 & 3 & 3 & 3 & 3 & 3 & 3 & 3 & Hoop \\
\hline Cylinders & 3 & 3 & 3 & 3 & 3 & 3 & 3 & 3 & 3 & Hoop \\
\hline Prisms & 3 & 3 & 3 & 3 & 3 & 3 & 3 & 3 & 3 & Vertical \\
\hline
\end{tabular}

Experimental test results shows that BFRP wrapped specimens obtained more strength than conventional specimens. BFRP double wrapped specimens possess more strength than that of conventional specimens and single wrapped specimens. Based on the initial studies, BFRP double wrapping was adopted as the retrofitting technique for the further studies as it can bear more loads.

Table 3. Mean ultimate characteristicstrengths of concrete specimens

\begin{tabular}{|c|c|c|c|c|}
\hline \multirow{2}{*}{$\begin{array}{c}\text { Specimens \& Geometries in } \\
\text { mm }\end{array}$} & \multirow{2}{*}{$\begin{array}{l}\text { Curing } \\
\text { period }\end{array}$} & \multicolumn{3}{|c|}{ Ultimate characteristic stress in $\mathrm{N} / \mathrm{mm}^{2}$} \\
\hline & & Conventional & $\begin{array}{l}\text { Single BFRP } \\
\text { wrapping }\end{array}$ & $\begin{array}{l}\text { Double BFRP } \\
\text { wrapping }\end{array}$ \\
\hline \multirow{3}{*}{$\begin{array}{c}\text { Cube } \& 150 \times 150 \times \\
150 \text { (Compressive strength) }\end{array}$} & 7 days & 26.37 & 32.67 & 36.67 \\
\hline & 14 days & 31.18 & 35.77 & 47.25 \\
\hline & 28 days & 35.70 & 41.40 & 53.77 \\
\hline \multirow{3}{*}{$\begin{array}{l}\text { Cylinder } \& 150 \varnothing \& 300 \\
\text { length(Split tensile strength) }\end{array}$} & 7 days & 3.13 & 4.12 & 5.75 \\
\hline & 14 days & 3.53 & 5.92 & 7.64 \\
\hline & 28 days & 3.97 & 6.25 & 8.18 \\
\hline \multirow{3}{*}{$\begin{array}{l}\text { Prism \& } 100 \times 100 \times 500 \text { length } \\
\text { (SFlexural strength) }\end{array}$} & 7 days & 2.64 & 4.81 & 7.08 \\
\hline & 14 days & 3.59 & 6.75 & 8.10 \\
\hline & 28 days & 4.18 & 9.28 & 10.15 \\
\hline
\end{tabular}

The following procedures were followed for preparation of concrete specimens for retrofitting works. After 28 days of normal curing, the conventional specimens were fatigue load or preloaded with $30 \%, 60 \%$ and $90 \%$ of ultimate characteristic loads. Then the preloaded specimens were confined or wrapped with basalt uni-directional fibre by using epoxy adhesive with cited orientation; it is given in Table 2. After that the specimens were kept idle for 36 to 48 hours for setting of BFRP wraps. After setting, the specimens like cubes, cylinders and prisms were tested in compressive testing machine and UTM for finding out the compressive strength, split tensile strength and flexural strength respectively. The test setups are given in Figure 1. The test results were obtained, analyzed and tabulated in Table 3 and plotted in Figure $2-4$. 

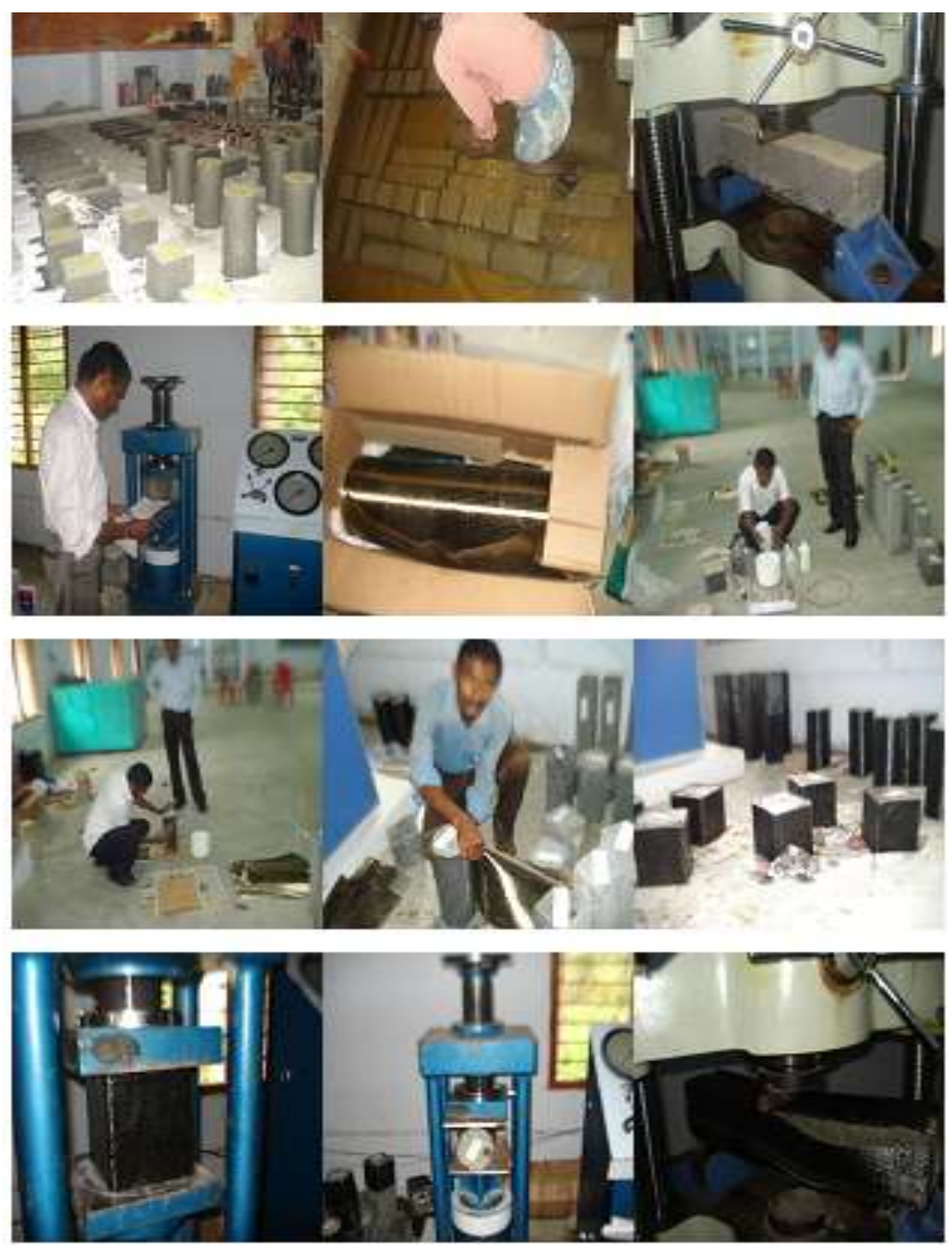

Fig. 1: Concrete specimens casting and testing details

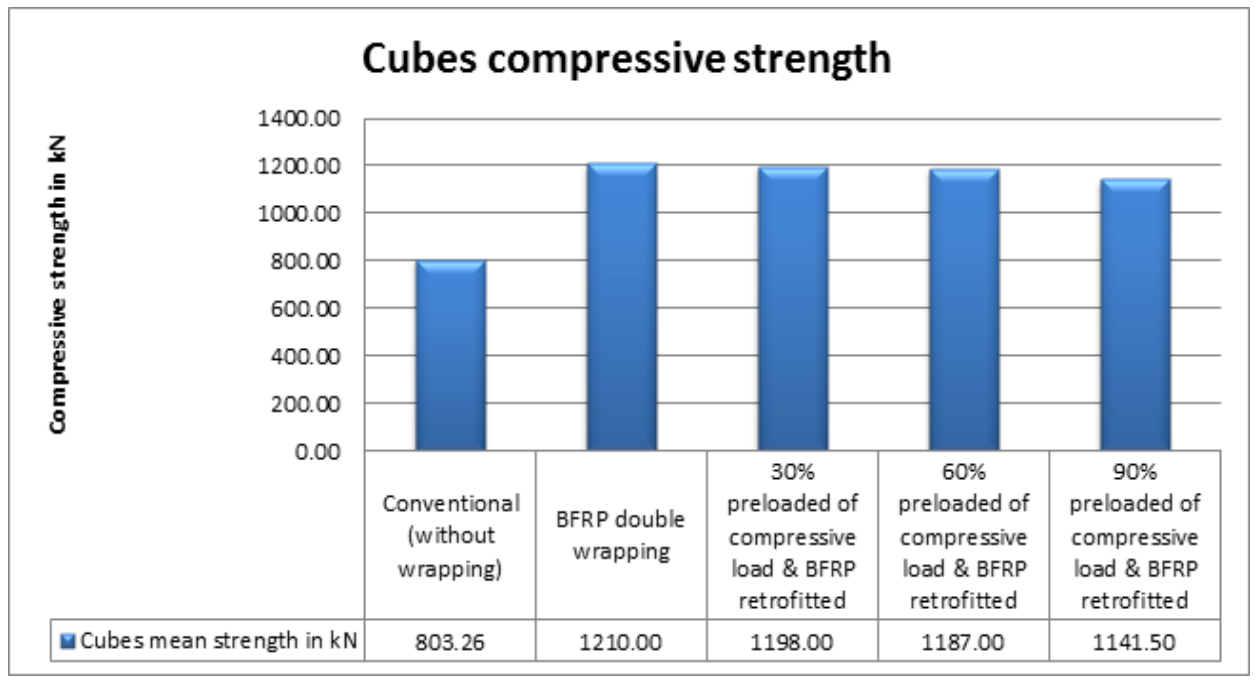

Fig. 2: Compression test on cubes 


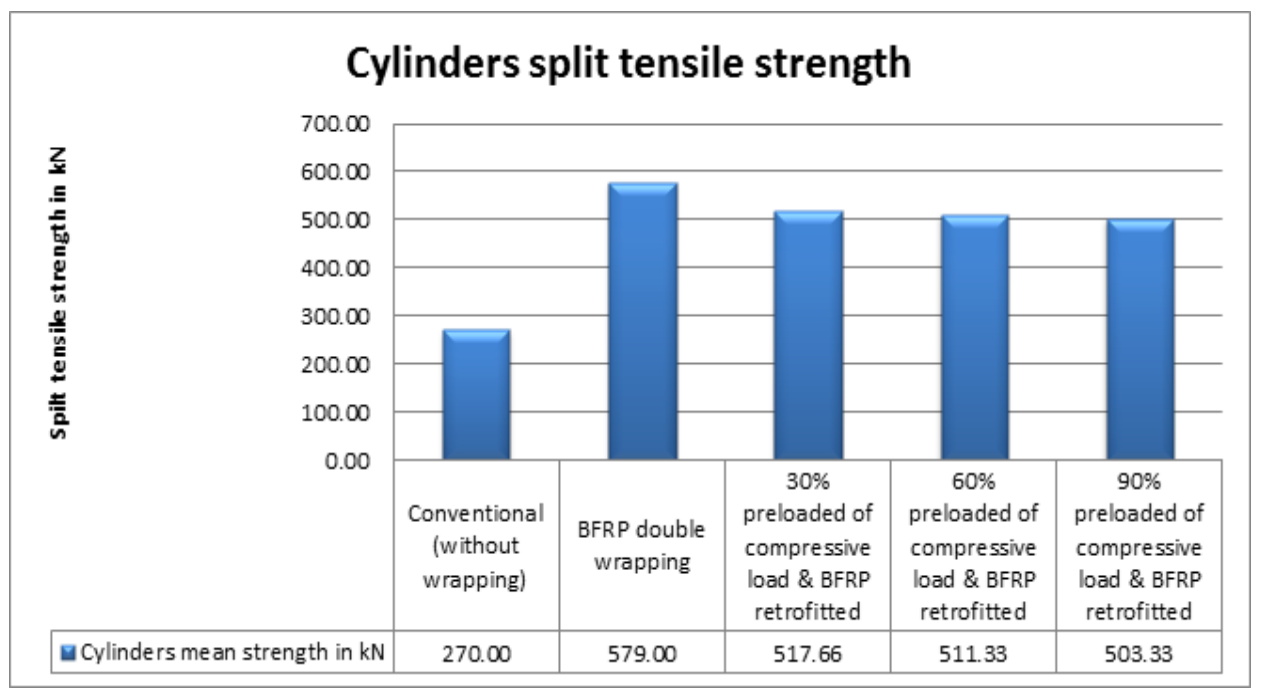

Fig. 3: Split tensile test on cylinders

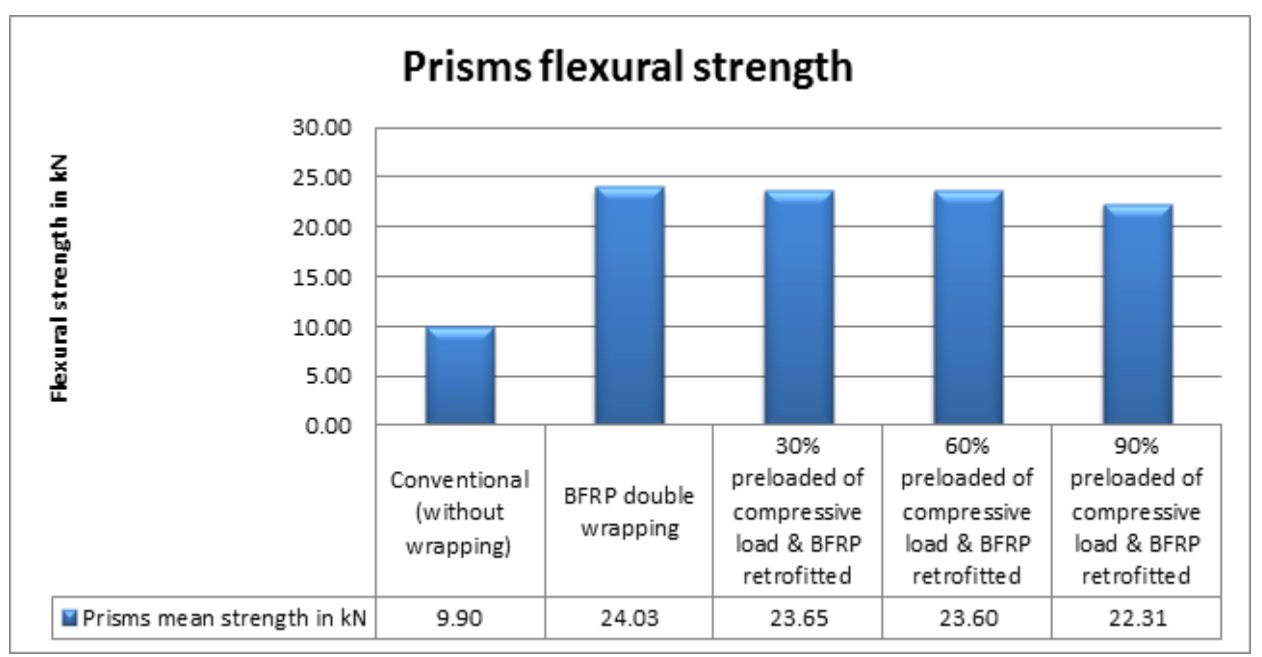

Fig. 4: Flexural test on prisms

\section{RESULTS AND DISCUSSION}

\subsection{Performance of specimens}

The mean compressive strength of conventional, BFRP single wrapped, BFRP double wrapped cube specimens are 35.70 $\mathrm{N} / \mathrm{mm}^{2}, 41.40 \mathrm{~N} / \mathrm{mm}^{2}$ and $53.77 \mathrm{~N} / \mathrm{mm}^{2}$ respectively which is tabulated in Table 3 . The double BFRP wrapped specimens showed more strength than conventional and BFRP single wrapped cube specimens. This increment in strength is due to the enhancement of stiffness and slight increase in moment of inertia caused by the BFRP layers.

Figure 2 shows that the cube specimens retrofitted with BFRP double wrapping after $30 \% 60 \%$ and $90 \%$ of fatigue loading or preloading were attained more compressive strength than conventional specimens. The double layer wrapping of BFRP on $90 \%$ fatigue loaded cube specimens showed 1.42 times increase of strength than the conventional specimens.

Similarly, the mean split tensile strength of conventional, BFRP single wrapped, BFRP double wrapped cylinder specimens are $3.97 \mathrm{~N} / \mathrm{mm}^{2}, 6.25 \mathrm{~N} / \mathrm{mm}^{2}$ and $8.18 \mathrm{~N} / \mathrm{mm}^{2}$ respectively as tabulated in Table 3. The double layer BFRP wrapped specimens possess more strength than conventional and BFRP single wrapped specimens.

Figure 3 shows that the cylinder specimens retrofitted with BFRP double wrapping after $30 \% 60 \%$ and $90 \%$ of fatigue loading or preloading attained more split tensile strength than conventional specimens. The double layer wrapping of BFRP on $90 \%$ preloaded elements enhances the strength by 1.86 times than the conventional specimens.

Similarly, the mean flexural strength of conventional, BFRP single wrapped, BFRP double wrapped prism specimens are $4.18 \mathrm{~N} / \mathrm{mm}^{2}, 9.28 \mathrm{~N} / \mathrm{mm}^{2}$ and $10.09 \mathrm{~N} / \mathrm{mm}^{2}$ respectively; it is also given in Table 3. The double BFRP wrapped specimens were attained more strength than conventional and BFRP single wrapped specimens. 
Figure 4 shows that the prism specimens retrofitted with BFRP double wrapping after $30 \% 60 \%$ and $90 \%$ of fatigue loading attained more flexural strength than conventional specimens. BFRP double wrapping on $90 \%$ preloaded specimens enhances the strength by 2.25 times the strength of conventional specimens. The orientation of the fibre warps along the vertical direction plays a predominant role in enhancing the flexural and tension strength of the prism specimens. From the experimental results and observed data, mathematical predictions were determined with constants for compressive stress, split tensile stress and flexural stress of cubes, cylinders and prisms respectively.

\subsection{Determination of mathematical prediction for cube compressive stress}

Characteristic compressive strength of the concrete mix $f c k$

Experimental characteristics compressive stress of concrete cubes $f c k e$

$$
\begin{array}{ll}
= & 30 \mathrm{~N} / \mathrm{mm} 2 \\
= & k 1 f c k
\end{array}
$$

Characteristic compressive stress of BFRP double wrapped concrete cube $f c k w=f c k e \mathrm{Cc}$

Where, $C c$ is a concrete cube constant and its value is arrived as 1.5 for all design calculation.

Compressive strength of retrofitted concrete cubes $f c k \mathrm{r}=\quad=\quad f c k w$ Rc or $\mathrm{k} 1 f c k C c \mathrm{R} c$

Where, the value of Rc retrofitting constant is taken from graph shown in Figure 5 which is arrived based on experimental results.

For BFRP double wrapped cube specimens preloaded to $30 \%$, the mean compressive strength of conventional cube is calculated from constants as follows:

Using eqn. (4) Ultimate stress of retrofitted specimens $f c k r=f c k w$ Rc or $k 1 f c k C c R c$

Rc value is taken as 0.994 from graph shown in Figure 5.

$$
\begin{aligned}
& =1.19 \times 30 \times 1.50 \times 0.994 \\
& =53.22 \mathrm{~N} / \mathrm{mm} 2
\end{aligned}
$$

BFRP double wrapped cube specimens preloaded to $60 \%$, the mean compressive strength of conventional cube is calculated from constants as follows:

Rc value is taken as 0.98 from graph shown in Figure 5 .

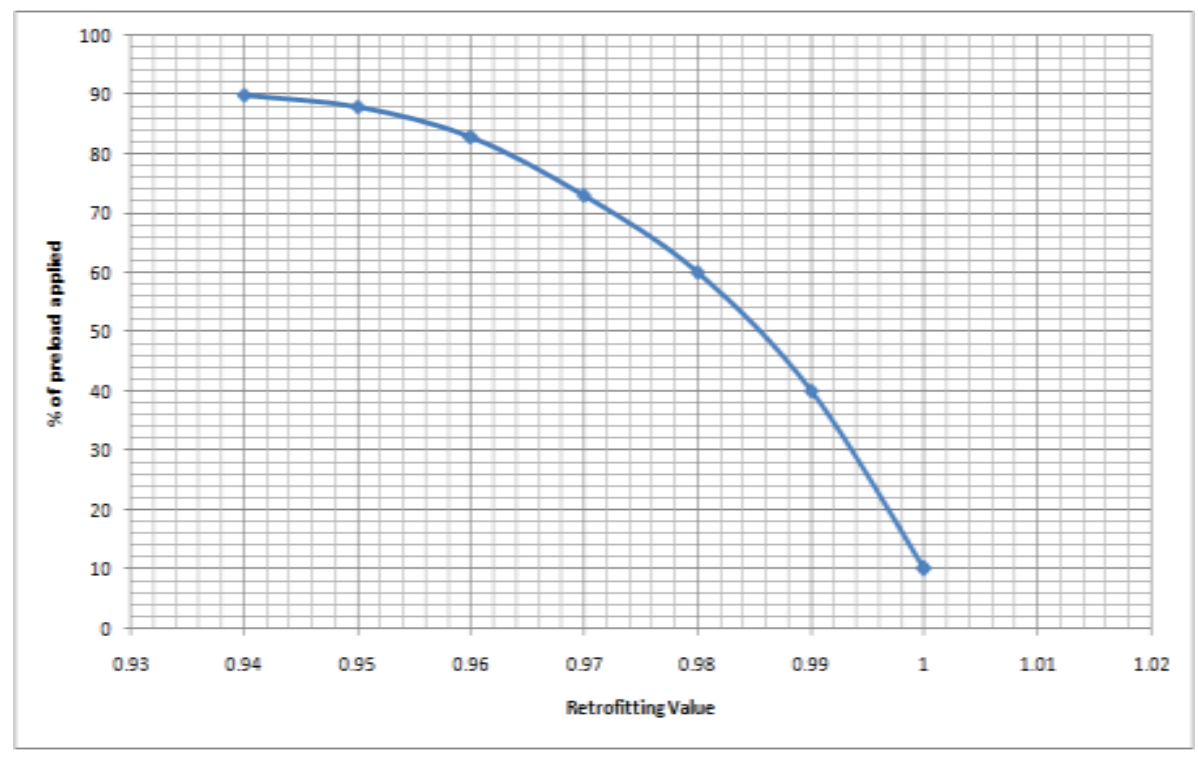

Fig. 5: Retrofitting constant $\mathbf{R}_{\mathbf{c}}$ for compressive strength

Using eqn. (4) Ultimate stress of retrofitted specimens $f c k r$

$$
\begin{aligned}
& =1.19 \times 30 \times 1.50 \times 0.98 \\
& =52.47 \mathrm{~N} / \mathrm{mm} 2
\end{aligned}
$$

BFRP double wrapped cube specimens preloaded to $90 \%$, the mean compressive strength of conventional cube is calculated from constants as follows:

Rc value is taken as 0.90 from graph shown in Figure 5.

Using eqn. (4) Ultimate stress of retrofitted specimens $f c k r$

$$
\begin{aligned}
& =1.19 \times 30 \times 1.50 \times 0.90 \\
& =50.33 \mathrm{~N} / \mathrm{mm} 2
\end{aligned}
$$

\subsection{Determination of mathematical prediction for split tensile stress}


For M30 grade concrete cylinders, split tensile stress $f \mathrm{c}$

Experimental characteristic split tensile stress of concrete cylinders $f$ ce

$$
\begin{aligned}
& =0.7 \sqrt{ } f c k \mathrm{~N} / \mathrm{mm} 2 \\
& =k 1 f c
\end{aligned}
$$

Characteristic split tensile stress of BFRP double wrapped concrete cylinders $f \mathrm{cw}=f c e \mathrm{Ct}$

Where, $C t$ is a concrete cylinder constant and which is arrived as 2.145 for all design calculation.

Split tensile strength of retrofitted concrete cylinder $f c k r=f c w$ Rt or $k 1 f c C t$ Rt

Where, Rt retrofitting constant value is taken from graph shown in Figure 6 which was developed based on experimental results.

For BFRP double wrapped cylinder specimens preloaded to $30 \%$, the mean split tensile strength of conventional cylinder is calculated from constants as follows:

Using eqn. (8) Ultimate stress of retrofitted cylinder specimens $f c k r=f c w$ Rt or $k 1 f c k C t$ Rt

Rt value is taken as 0.8725 from graph shown in Figure 6.

$$
\begin{aligned}
& =0.996 \times(0.70 \sqrt{ } 30) \times 2.145 \times 0.8725 \\
& =7.146 \mathrm{~N} / \mathrm{mm} 2
\end{aligned}
$$

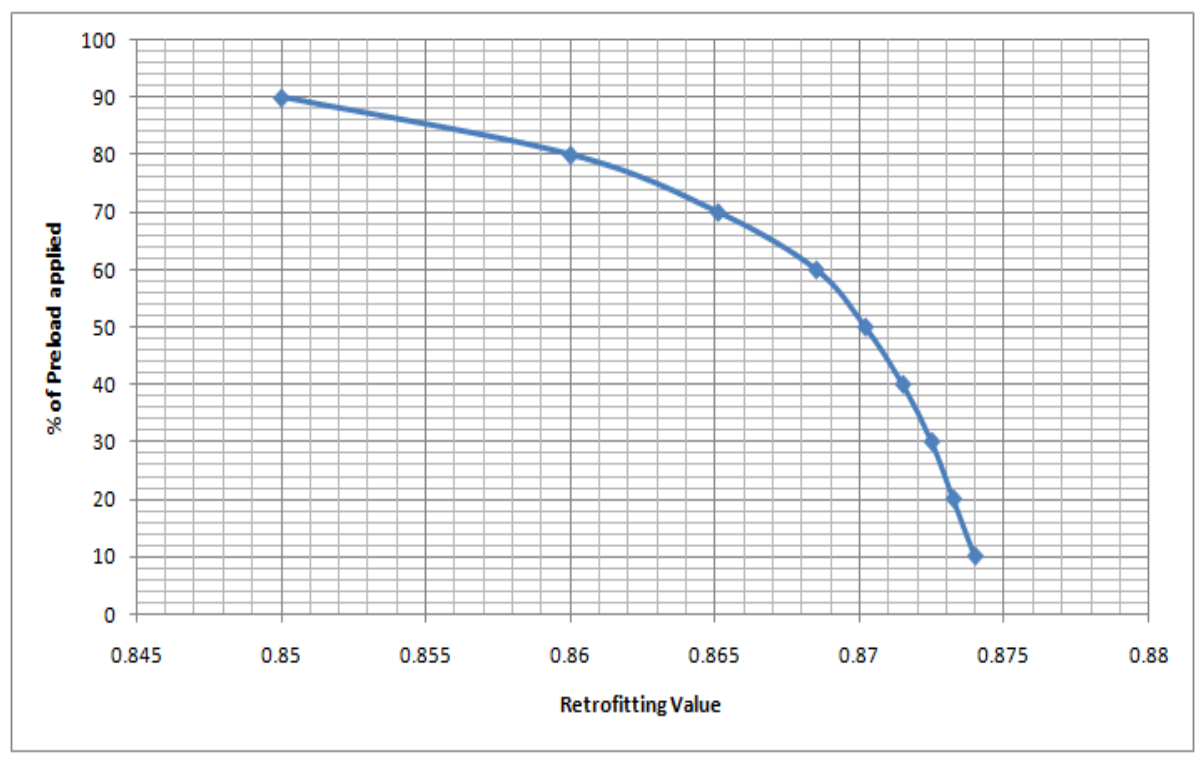

Fig.6: Retrofitting constant Rt for split tensile strength

For BFRP double wrapped cylinder specimens preloaded to $60 \%$, the mean split tensile strength of conventional cylinder is calculated from constants as follows:

Using eqn. (8) Ultimate stress of retrofitted cylinder specimens $f c k r=f c w$ Rt or $k 1 f c k C t$ Rt

Rt value is taken as 0.8685 from graph shown in Figure $6 .=0.996 \times(0.70 \sqrt{ } 30) \times 2.145 \times 0.8685=7.113 \mathrm{~N} / \mathrm{mm} 2$

BFRP double wrapped cylinder specimens preloaded to $90 \%$, the mean split tensile strength of conventional cylinder is calculated from constants as follows:

Using eqn. (8) Ultimate stress of retrofitted cylinder specimens $f c k r=f c w$ Rt or $k 1 f c k C t$ Rt

Rt value is taken as 0.85 from graph shown in Figure 6.

$$
\begin{aligned}
& =0.996 \times(0.70 \sqrt{30}) \times 2.145 \times 0.85 \\
& =6.962 \mathrm{~N} / \mathrm{mm} 2
\end{aligned}
$$

\subsection{Determination of mathematical prediction for flexural stress}

For M30 grade concrete prisms, flexural stress $f \mathrm{p}$

$=0.7 \sqrt{ } f c k \mathrm{~N} / \mathrm{mm} 2$

Experimental characteristic flexural stress of concrete prisms $f \mathrm{pe}$

$=k 1 \mathrm{fp}$

Where, $k 1$ is a constant and its value is arrived as 1.085 for all design calculation.

Characteristics flexural stress $f c k w$ of BFRP double wrapped concrete cube is $f p w$

$=f \mathrm{p} e C f$ 
Where, $C f$ is a concrete prism constant and its value is arrived as 2.426 for all design calculation.

Flexural strength of retrofitted concrete prism $f c k r$

$=f \mathrm{pw} \operatorname{Rf}$ or $k 1 f \mathrm{ck} C \mathrm{ff}$

Where, Rf retrofitting constant value is taken from graph shown in Figure 7 which was arrived based on experimental results.

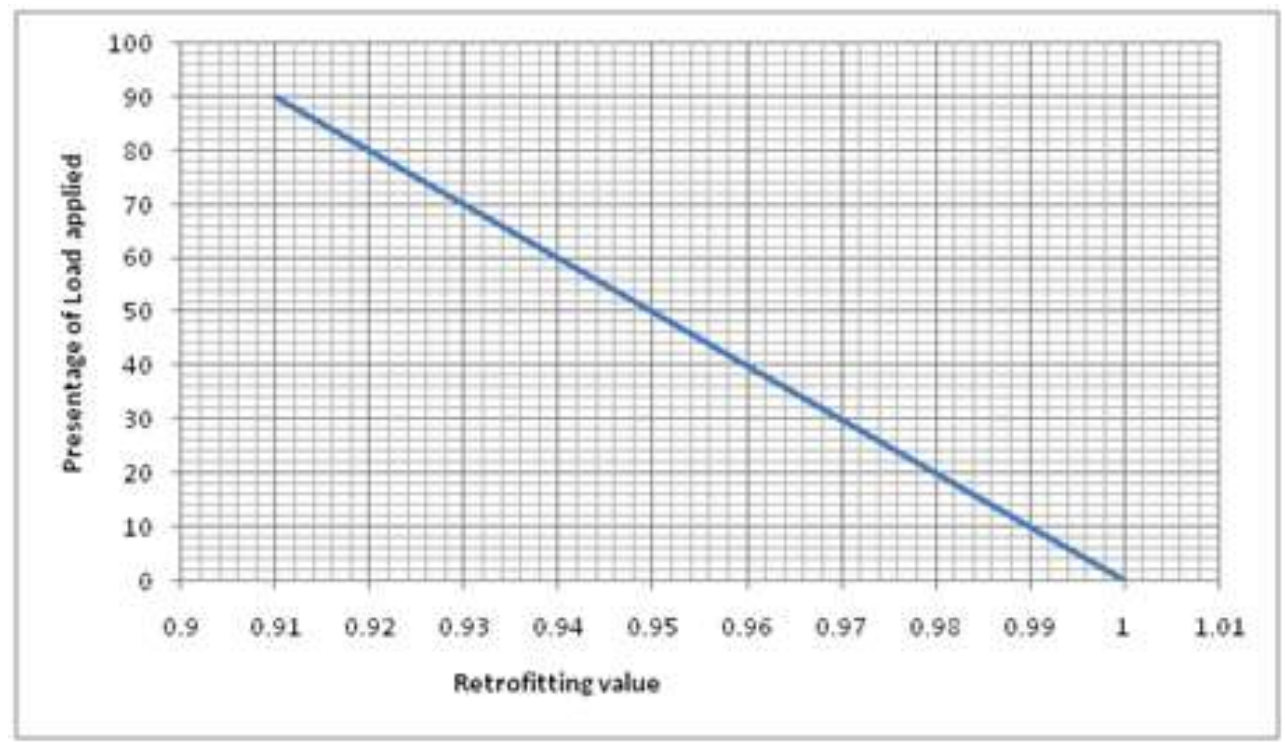

Fig. 7: Retrofitting constant Rf for flexural strength

For BFRP double wrapped prism specimens preloaded to $30 \%$, the mean flexural strength of conventional prisms is calculated from constants as follows:

Using eqn. (12) Ultimate stress of retrofitted prism specimens $f \mathrm{pr}$

$=f \mathrm{pw} \operatorname{Rf}$ or $k 1 f \mathrm{ck} C \mathrm{Rf}$

Rf value is taken as 0.97 from graph shown in Figure 7 .

$$
\begin{aligned}
& =1.085 \times(0.70 \sqrt{30}) \times 2.426 \times 0.97 \\
& =9.789 \mathrm{~N} / \mathrm{mm} 2
\end{aligned}
$$

BFRP double wrapped prism specimens preloaded to60\%, the mean flexural strength of conventional prisms is calculated from constants as follows:

Using eqn. (12) Ultimate stress of retrofitted prism specimens $f \mathrm{pr} \quad=f \mathrm{p} w$ Rf or $k 1 f \mathrm{ck} C \mathrm{Rf}$

$\mathrm{Rf}$ value is taken as 0.94 from graph shown in Figure 7.

$$
\begin{aligned}
& =1.085 \times(0.70 \sqrt{ } 30) \times 2.426 \times 0.94 \\
& =9.486 \mathrm{~N} / \mathrm{mm} 2
\end{aligned}
$$

BFRP double wrapped prism specimens preloaded to $90 \%$, the mean flexural strength of conventional prisms is calculated from constants as follows:

Using eqn. (12) Ultimate stress of retrofitted prism specimens $f \mathrm{pr} \quad=f \mathrm{pw}$ Rf or $k 1 f \mathrm{ck} C \mathrm{fRf}$

Rf value is taken as 0.91 from graph shown in Figure 7.

$$
\begin{aligned}
& =1.085 \times(0.70 \sqrt{ } 30) \times 2.426 \times 0.91 \\
& =9.183 \mathrm{~N} / \mathrm{mm} 2
\end{aligned}
$$

From the Table 4, the values of the mathematical prediction resemble with the experimental results; no major changes are observed between them. Hence, the mathematical prediction can be incorporated for calculation of the strength of retrofitted specimens theoretically.

Table 4. Theoretical and Analytical Results 


\begin{tabular}{|c|c|c|}
\hline \multirow{2}{*}{ Type of specimens } & \multicolumn{2}{c|}{$\begin{array}{c}\text { Characteristic stress of BFRP double } \\
\text { wrapped concrete specimens in N/mm2 }\end{array}$} \\
\cline { 2 - 3 } & $\begin{array}{c}\text { Mathematical } \\
\text { Prediction } \\
\text { Eesults }\end{array}$ & 53.77 \\
\hline BFRP double wrapped cubes & 53.77 & 53.22 \\
\hline $30 \%$ Preloaded \& Retrofitted with BFRP cubes & 53.24 & 52.47 \\
\hline $60 \%$ Preloaded \& Retrofitted with BFRP cubes & 52.75 & 50.33 \\
\hline $90 \%$ Preloaded \& Retrofitted with BFRP cubes & 50.73 & 8.18 \\
\hline BFRP double wrapped cylinders & 8.18 & 7.10 \\
\hline $30 \%$ Preloaded \& Retrofitted with BFRP cylinders & 7.32 & 7.07 \\
\hline $60 \%$ Preloaded \& Retrofitted with BFRP cylinders & 7.22 & 6.92 \\
\hline $90 \%$ Preloaded \& Retrofitted with BFRP cylinders & 7.12 & 10.09 \\
\hline BFRP double wrapped prisms & 10.09 & 9.78 \\
\hline $30 \%$ Preloaded \& Retrofitted with BFRP prisms & 9.93 & 9.48 \\
\hline $60 \%$ Preloaded \& Retrofitted with BFRP prisms & 9.91 & 9.18 \\
\hline $90 \%$ Preloaded \& Retrofitted with BFRP prisms & 9.37 & \\
\hline
\end{tabular}

\section{CONCLUSION}

The experimental results prove that BFRP wrapping aids in increasing the strengths both in normal concrete and retrofitted specimens. The BFRP retrofitted after $30 \%, 60 \%$ and $90 \%$ of fatigue loading or preloading cube specimens withstood compressive strength 1.49 times, 1.47 times and 1.42 times more than the conventional ones. Similarly, the cylinders withstood split tensile strength 1.91 times, 1.89 times \& 1.86 times and the prisms withstood flexural strength 2.38 times, 2.38 times \& 2.25 times more than the conventional ones. The BFRP wrapped in length directions resist against deformations and thus enhancement in tensile strengths. BFRP warp orientation in hoop direction over the specimens withstands more compressive strength and split tensile strength than conventional specimens. Moreover, the elastic behaviours of BFRP wrapped specimens are more effective than the conventional. The novelty mathematical prediction evaluated from this study; can be used for finding out the strength parameters of fatigue loaded and retrofitted specimen. The formula can also be used to find out the load carrying capacity of retrofitted existing structural elements on site. Future research should be made to focus on the application of this prediction in designing of RCC elements and preparation of standards.

\section{REFERENCES}

1. Tamer, El.M., Khaled, S., and Tim, T. 2005. Computer-based mathematical model for performance prediction of beams repaired with fiber reinforced polymers. Journal of composites for construction, 9 (3), 227-235.

2. Mostofinejad, D., and Saadatmans, H. 2010. A procedure for predicting the behaviour of FRP confined concrete using FE method. Transaction A: Civil engineering, 17(6), 471-481.

3. Shende, A.M., and Pande, A.M. 2011. Experimental study and prediction of tensile strength for steel fiber reinforced concrete. International journal of civil and structural engineering, 1(4), 910-917.

4. Nibudey, R.N., Nagarnaik, P.B., Parbat,D.K., and Pande, A.M. 2013. Strengths prediction of plastic fibre reinforced concrete (M30). International journal of engineering research and applications, 3(1), 1818-1825.

5. Murugan, M., Natarajan, C., and Muthukumaran, K. 2013. Compressive behaviour of concrete cylinders confined with glass and carbon fibre reinforced polymers. International journal of structural and civil engineering research, 2(2), 69- 76.

6. Gunneswra rao, T.D., Mudimby, A., Sahu, S., and Putcha, C. 2015. Probabilistic assessment on flexural strength of steel fiberreinforced concrete members. International journal of engineering research and general science, 3(1), 520-527.

7. Dhevasenaa, P.R., Suguna, K., and Raghunath, P.N. 2015. Regression model for predicting study parameters of GFRP strengthened corrosion damaged RC columns. International journal of engineering science and innovative technology, 4(2), 223-231.

8. Anandakumar, R., Selvamony, C., and Kannan, S.U. 2013. Retrofitting of Concrete Specimens and Reinforced Concrete Piles Using Basalt Fibers. International Journal of Engineering Science Invention, 2(8), 1-5. 
9. Anandakumar, R. Selvamony, C., and Seeni, A. 2014. Experimental Study of BFRP Retrofitted RCC Piles Elastic Behaviours Subjected to Axial Load. International Journal of Earth Sciences and Engineering, 7(5), 1079-1085.

10. Anandakumar, R. Selvamony, C., and Seeni, A. 2014. Performance of BFRP retrofitted RCC piles subjected to axial loads. International journal Advances in Materials Science and Engineering, 2014, 1-9. http://dx.doi.org/10.1155/2014/323909.

11. Anandakumar, R. Selvamony, C., Seeni, A., and Ravikumar, M.S. 2014. Durability study on Basalt Fibre Reinforced Polymer (BFRP) Composites Wrapped Specimens for Retrofitting of RCC piles. International Journal of Engineering Research \& Technology, 3(3), 315-320.

12. Bureau of Indian Standards, IS 8112 - 1989: Specification for 43 grade ordinary Portland cement, Bureau of Indian Standards, Manak Bhavan, 9 Bahadur Shah Zafar marg, New Delhi.

13. Bureau of Indian Standards, IS 4031 - 1996 (Part 1-15): Indian Standard Methods Of Physical Tests For Hydraulic Cement, Bureau of Indian Standards, Manak Bhavan, 9 Bahadur Shah Zafar marg, New Delhi.

14. Bureau of Indian Standards, IS 383 - 1970: Specification for coarse and fine aggregates from natural sources for concrete, Bureau of Indian Standards, Manak Bhavan, 9 Bahadur Shah Zafar marg, New Delhi.

15. Bureau of Indian Standards, IS 3025 - 1964: Methods of Sampling and Test (Physical and Chemical) for Water Used inMIndustry, Bureau of Indian Standards, Manak Bhavan, 9 Bahadur Shah Zafar marg, New Delhi.

16. Basalt fibre properties, 2013. [Online] Available: http:/www.basaltfibre-gbf.com, (March 21, 2013)

17. Epoxy properties, 2013. [Online] Available: http://www.silmid.com, (March 21, 2013)

18. Bureau of Indian Standards, IS 10262 - 1982: Recommended guidelines for concrete mix design, Bureau of Indian Standards, Manak Bhavan, 9 Bahadur Shah Zafar marg, New Delhi.

19. Bureau of Indian Standards, IS 516 - 1959: Method of test for strength of concrete, Bureau of Indian Standards, Manak Bhavan, 9 Bahadur Shah Zafar marg, New Delhi. 